\title{
RECOMMENDATIONS FOR THE SAFE USE OF ROPEWAYS CARRYING EXPLOSIVES IN AVALANCHE BLASTING
}

\author{
by
}

\author{
Gerard Brugnot and Francois Rapin
}

(CEMAGREF, Division Nivologie, BP 76, 38402 Saint-Martin-D'Hères Cédex, France)

\section{ABSTRACT}

Over 15 years of experience, and a present stock of nearly 140 devices, have made us familiar with the use of avalanche-blasting ropeways (CATEX) in artificial avalanche release. Two years ago, in consultation with all other users we started to establish a list of recommendations for the safe use of CATEX, so that efficiency and reliability could be improved considerably. These guidelines have been designed to achieve safety by adapting CATEX technology to avalanche problems concerned with mechanical equipment, explosives, staff and maintenance.

\section{INTRODUCTION}

CATEX (the French acronym for "explosive carrying cable") technology has been used increasingly during the last 15 years, especially in Austria and in France, for causing the artificial release of avalanches. The device offers the following combination of specific advantages for avalanche protection:

Once at the driving station, it is always possible to operate the equipment simply and quickly under any weather condition and at any time.

The explosion takes place above the snow cover, the optimal height above snow cover for blasting being between 1 and $5 \mathrm{~m}$, and in such conditions $80 \%$ of detonations release avalanches.

Distant and/or inaccessible starting zones can be reached.

Investment costs are far below those of permanent avalanche-prevention structures, such as snow or road shields, when the area to be covered is large (greater than 1 ha).

Operating costs are low, consisting primarily of staff costs during operations.

Automatic use of safety fuses for detonation reduces risks from the manipulation of explosives and allows recovery of any non-exploded charge.

Some disadvantages, however, must be mentioned:

Artificial release of avalanches cannot be recommended for protection of inhabited areas.

Implementation is almost impossible where pylons have to be set up in an area of avalanche high-risk.

Environmental and/or safety considerations may prohibit the construction of towers and the laying of cables.

Costs are high compared with the use of hand blasting. Once a CATEX has been built it may be difficult to correct errors in its design and, if pylons have to be moved, this is a costly operation.

From the technical point of view, a CATEX is a ski-lift with a driving station, pylons, pulleys and a moving cable. The system carries only explosives, not people and as a result some of the safety arrangements necessary in ski-lifts carrying people may be dispensed with, although, on the other hand, there are also safety provisions which must be reinforced. For example, the system must withstand severe weather conditions caused by wind, frost, etc., and because it conveys explosives there are special controls including the fuse-obligation and minimum safety distances whenever radio transmitters are used.

About 250 CATEX have been built so far, of which more than 140 are in France and one has a cable length of over $7.6 \mathrm{~km}$. Because of the widespread use of CATEX it has become necessary in France to produce regulations governing the use of the technique, in order both to prevent new users such as entrepreneurs, owners, and technicians from making mistakes, and to improve the reliability of the system (Rapin and Brugnot, 1988).

\section{MAIN RECOMMENDATIONS}

\section{CATEX techniques}

Before building a CATEX one must be certain that artificial avalanche release is a technically feasible solution for providing the required level of protection. A risk study must be made to assess potential damage to life and property; and as a general rule risk of accident to people or buildings is unacceptable but risk of damage to ski-lifts may sometimes be tolerated.

Roads must be closed during avalanche release operations. Explosives should be water- and frost-resistant, with detonation speeds greater than $5000 \mathrm{~m} / \mathrm{s}$. Gelatine dynamites, which are approximately $40 \%$ nitroglycerine, are of ten used although nitrates may be used if the packaging is watertight. A seismic tube package of $2.5 \mathrm{~kg}$ is most widely used, because it withstands jolts during transit.

It is crucial to locate the CATEX driving station outside the avalanche zone, with easy access even under bad weather conditions. This is particularly important when avalanche control operations are needed during snow storms or to protect highways or main ski-runs. Pylons have to be placed in positions not at risk from avalanches. If necessary, they should be protected against avalanche forces by the use of wedges or by reinforcement.

The advantages and disadvantages of using CATEX as compared with other protective systems should be assessed in the light of the principal rules for artificial avalanche release (Gubler, 1983).

\section{Construction}

Experience shows that CATEX efficiency is increased if three conditions are fulfilled. These are that:

The blasting points should be fixed in collaboration with an avalanche expert and with local people, especially when they know the site well and have practical experience of artificial avalanche release at this site.

A topographical survey should be performed in order to determine whether the cable will be clear of the snow surface. Three profiles must be drawn; one for the unloaded system, another one with the largest expected explosive weight and a third for cable covered with ice, to make possible the calculation of pylon heights and of the likely stresses on the pylons, 
pulleys and cable. This is all the more important when descenders are to be used, since these electronic devices may be damaged by encountering obstacles. (Snow-drifting must also be considered at this stage of the project.)

Potential effects of wind, rime, and possibly avalanches should be taken into account. In addition to normal operational loads two cases must be considered for wind stress, namely that when the CATEX is moving it is subjected to a stress of $300 \mathrm{~Pa}$ and that when the CATEX is at rest it experiences a horizontal stress of $2500 \mathrm{~Pa}$ and a vertical stress of $500 \mathrm{~Pa}$. When rime is a major factor then automatic running of the CATEX at time intervals of about $5 \mathrm{~min}$ may be recommended as being most suitable.

A study of the site may help to reduce the number of necessary pylons and to assess their optimal height. In addition it seems essential to ensure a correct initial alignment and frequent maintenance in order to prevent wear on pulleys.

\section{Explosives}

In most cases the charge is triggered by a detonator which is itself triggered by a fuse. Therefore the problem is to have a sufficiently long time lapse for the fuse, so that the load can reach the blasting point before exploding. However, this simple system has three major drawbacks:

Once the load is sent along the ropeway there is no possibility of stopping the operation in the event of engine or power failure.

If several distant blastings need to be performed the duration of the operation will become very long.

During transport the load is situated at a fixed and rather short distance from the cable, so that it can be well clear of the snow surface when it arrives at the blasting point. The load-bearing rope could be burned by the fuse and so drop the load. For this reason the simple system fails to meet the requirement of French law that exploded charges must be retrieved, and so is illegal in France.

For the reasons mentioned more above sophisticated systems called descenders have been introduced, which can retrieve unexploded loads. Owing to electrostatic problems encountered in high mountains, especially around metallic objects in motion, activating explosives directly by means of a source of electric energy is forbidden. Igniting a fuse more than $1 \mathrm{~m}$ long activates the detonator about $1 \frac{1}{2} \mathrm{~min}$ later. Selecting on a timer a value of $1 \mathrm{~min}$ or more before each operation cannot control the precise timing of the explosion, since the process cannot be stopped once the load is sent along the cable. Radio control of fuse lighting, and consequently also of the explosion, is increasingly used for long CATEX because it provides the possibility of controlling blasting up to the last moment. Such radio control is mandatory if a CATEX system crosses an avalanche starting zone which must not be triggered, for example where buildings are involved. Radio operators must be equipped with mechanical and electronical safety devices, and ignition should only be authorized upon completion of a strict procedure without which the system must automatically return to a passive waiting position. A special high-intensity ignition system that is protected against static electricity and humidity and has a reinforced filament has been designed specially for CATEX with the aim of reducing the risks of fuse ejection.

Advanced descenders can place an explosive charge at the desired distance from the snow surface. This particular distance is selected separately before each operation. The use of radio command enables the monitoring of the explosive system since all descenders can emit information such as charge position ready, explosion completed, misfire, etc.

The rules require that a CATEX system must be able to function correctly after a $3 \mathrm{~h}$ stand at $-30^{\circ} \mathrm{C}$. This is a severe test for descenders owing to the fact that they contain electronic components, but experience has shown that this provision is both essential and realistic. As far as long CATEX arrangements are concerned it is convenient to attach several explosive charges to a cable, each of which has its own descender controlled by either radio or a timing mechanism. The problem then is to slow down the driving engine whenever a charge passes a pulley. This can be done manually using a chart, or automatically if several descenders and pylons are involved. The use of an automatically-monitored system to slow down or to accelerate the CATEX engine progressively when necessary is recommended.

\section{Staff}

How well a CATEX system operates depends on the technical skills of the staff involved and the instructions they receive. The more sophisticated the equipment, the more competent the staff should be. Detailed instruction and staff training are likely to improve significantly the reliability of the machinery.

\section{CONCLUSION}

CATEX reliability and efficiency depends upon compliance with certain basic rules of design, construction, operation, and maintainance. If well designed, CATEX can be an efficient method of avalanche protection, and for this reason its use is already widespread in France. It should be noted that, in our experience, attempts to save money in construction of ten result in increases in operating costs.

\section{REFERENCES}

Brugnot, G. and F. Rapin. 1987. Recommandations applicables aux cables transporteurs d'explosifs, CATEX, destinés aux déclenchement des avalanches. Neige et Avalanches, 44, 37-49.

Gubler, H. 1978. Künstliche Auslösung von Lawinen durch Sprengungen. Mitt. Eidg. Inst. Schnee- und Lawinenforsch., 36. 